\title{
CAPACITANCE-VOLTAGE CHARACTERISTICS OF Si STRUCTURES IRRADIATED BY PROTONS AND THEIR FREQUENCY AND TEMPERATURE DEPENDENCES
}

\author{
S. Sakalauskas ${ }^{\mathrm{a}}$ and R. Pūras ${ }^{\mathrm{b}}$ \\ ${ }^{a}$ Faculty of Physics, Vilnius University, Sauletekio 9, LT-10222 Vilnius, Lithuania \\ ${ }^{\mathrm{b}}$ Institute of Materials Science and Applied Research, Vilnius University, Sauletekio 9, LT-10222 Vilnius, Lithuania \\ E-mail: romualdas.puras@ff.vu.lt
}

Received 5 March 2009; revised 3 August 2009; accepted 15 September 2009

\begin{abstract}
Experimental capacitance-voltage $(C-V)$ characteristics of silicon $p-i-n$ diodes irradiated with high energy protons and capacitance dependences on frequency and temperature are presented in the paper and results are discussed. The higher fluencies of proton irradiation lead to the larger capacitance values of diodes biased to reverse voltage in the range of 20-120 $\mathrm{Hz}$ frequency, given the other conditions are the same. The capacitances of irradiated diodes are considerably higher than the barrier capacitances of non-irradiated ones. The energy of dominant defect deep level was calculated according to analysis of capacitance-voltage dependences on frequency and temperature.
\end{abstract}

Keywords: silicon diode, capacitance spectroscopy, proton irradiation defects

PACS: 61.82.Fk, 71.55.Cn, 85.30.Kk

\section{Introduction}

Development of new functional electronic structures demands semiconducting materials with various properties. Nowadays the ionizing radiation is widely used for modification and control of semiconducting material properties [1-3]. Due to perfect modern technology processing of crystalline silicon and good compatibility of different silicon components with the highsensitivity electronic signal registration equipment a reasonably high attention is devoted to the investigation of silicon and its structure properties modified by an ionizing radiation. It is found that the hopping electrical conductivity of crystalline silicon affected by the ionizing radiation considerably exceeds its band conductivity. While the low-frequency capacitance of silicon monocrystal with a lot of radiation defects is considerably higher than that of a defectless one [4], the common and reasonable explanation to this is absent.

The goal of the present work is to find out the capacitance variation regularities of $\mathrm{Si} p-i-n$ diodes exposed to various fluencies of high energy particle radiation and biased to reverse voltage and to use these regularities for prediction of diodes' operation in electric circuits. Experimental capacitance-voltage characteristics of silicon diodes biased to reverse voltage and irradiated with high energy protons as well as their capacitance dependences on frequency and temperature are presented in the paper. The capacitance spectroscopy method was chosen to study the diodes as it provides a wealth of information on the objects under investigation [5].

\section{Specimens}

We investigated standard industrial caseless silicon $p$ - $i$ - $n$ diodes irradiated with protons. Junction area was $12 \mathrm{~mm}^{2}$, resistivity of $p$-layer was $0.004 \Omega \mathrm{cm}$, $i$-layer thickness $41 \mu \mathrm{m}$ and resistivity $25 \Omega \mathrm{cm}, n$-layer resistivity $0.04 \Omega \mathrm{cm}$. Proton irradiated region of a $\delta$-function form was created within $i$-layer about $7 \mu \mathrm{m}$ away from the technological $p-i$ junction. Other parameters are given in Table 1. The peculiarities of diode formation are presented in more detail in the paper [6]. The specimens were annealed after the measurements of capacitance-voltage $(C-V)$ characteristics in the dark at room and lower temperatures. Annealing was carried out at $353 \mathrm{~K}$ (first annealing) and next at $393 \mathrm{~K}$ (second annealing) temperature, duration of each annealing was 24 hours. 
Table 1. Parameters of irradiation of $p-i-n$ structures and structures' reverse currents.

\begin{tabular}{cccc}
\hline $\begin{array}{c}p-i-n \\
\text { structure, No }\end{array}$ & $\begin{array}{c}\text { Integrated irradiation } \\
\text { fluence, proton } / \mathrm{cm}^{2}\end{array}$ & $\begin{array}{c}\text { Proton energy, } \\
\mathrm{MeV}\end{array}$ & $\begin{array}{c}\text { Reverse current, } \\
\mu \mathrm{A}\left(U_{\mathrm{b}}=5 \mathrm{~V}\right)\end{array}$ \\
\hline 3 & $7 \cdot 10^{12}$ & 1.9 & 0.45 \\
9 & $7 \cdot 10^{13}$ & 1.9 & 4.0 \\
15 & $7 \cdot 10^{14}$ & 1.9 & 35.0 \\
21 & $7 \cdot 10^{12}$ & 2.0 & 1.0 \\
27 & $7 \cdot 10^{13}$ & 2.0 & 8.0 \\
33 & $7 \cdot 10^{14}$ & 2.0 & 50.0 \\
39 & non-irradiated & & 0.03 \\
\hline
\end{tabular}

\section{Measurement technique and instruments}

Various techniques and instruments may be used for capacitance measurement. Depending on the objective, we have used capacitance measuring instruments: operation of one technique is based on a capacitance divider method and another one on measuring the strength of specimen current created by a linearly varying voltage source. The first method does not warrant high accuracy but it allows to carry out measurements in wide frequency and voltage ranges, and another one enables an especially high speed of measurement. Our experiments carried out on proton irradiated silicon $p-i-n$ diodes revealed large uncertainties of these techniques due to large reverse currents in diodes, therefore we used high accuracy industrial capacitance measuring instruments E7-12 and Fluke PM6304. However, the mentioned devices have limited operation ranges and may not be used at high frequencies and high reverse voltages.

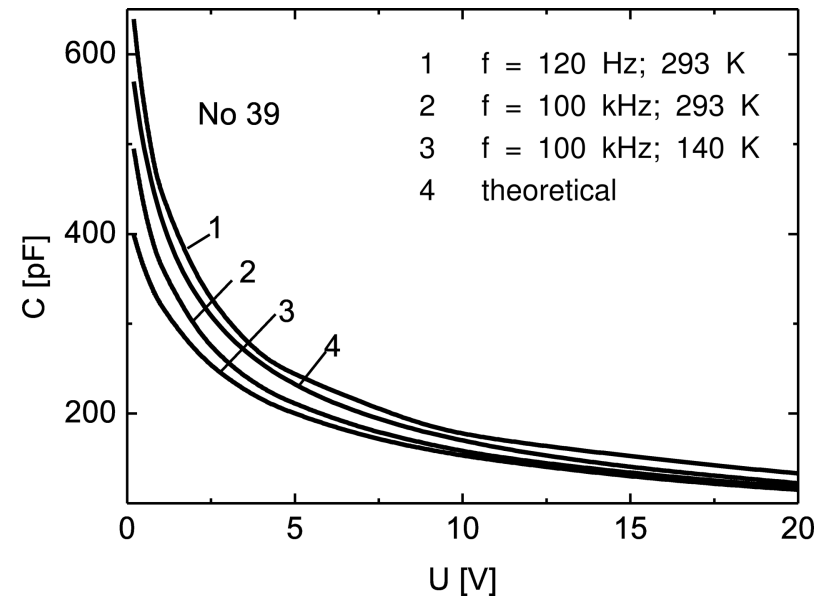

(a)

\section{Experimental results and discussion}

Experimental results are shown in Figs. 1-3. $C-V$ characteristics of a non-irradiated $p-i-n$ diode with the identical dimension and technological parameters (biased to reverse voltage) are shown in Fig. 1(a). The dependence of $C-V$ characteristics on frequency and temperature is small. The theoretical $C-V$ characteristic (curve 4), calculated according to classical theory of semiconductor junction barrier's capacity, coincides with experimental one within error limits. Other results were obtained with irradiated specimens. According to these results the higher fluencies of $p-i-n$ diode irradiation by protons lead to a larger capacitance of the diodes (under the reverse bias) in low frequency range, given other conditions and parameters are the same. The capacitance is considerably larger than the barrier capacitance of non-irradiated diodes (see Fig. 1(a, b)). In addition, it is found that the temperature (Fig. 2) and the frequency of a testing signal (Fig. 3) have strong influence on capacitance of irradiated specimens - structure's capacitance decreases with decreasing temperature and/or

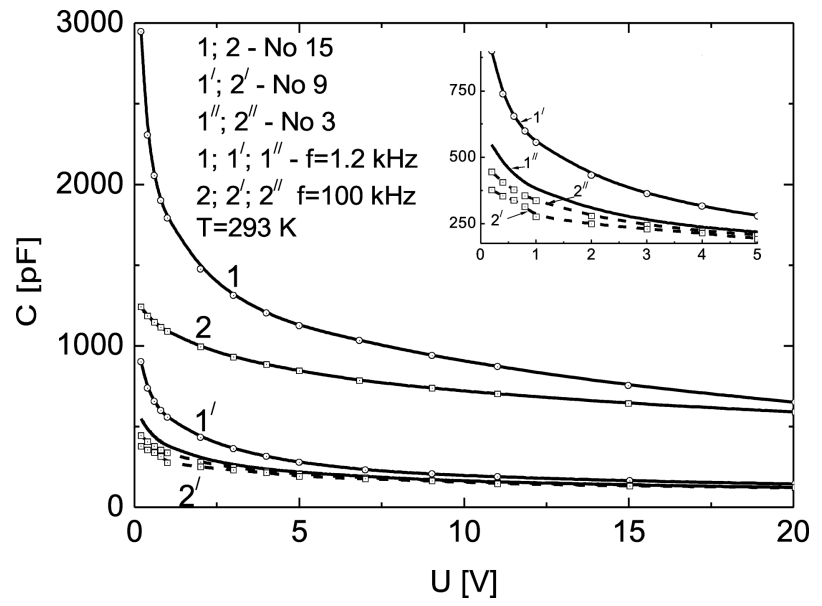

(b)

Fig. 1. Capacitance-voltage characteristics of (a) non-irradiated Si $p$ - $i$ - $n$ structure and (b) structures irradiated with $1.9 \mathrm{MeV}$ energy protons. 


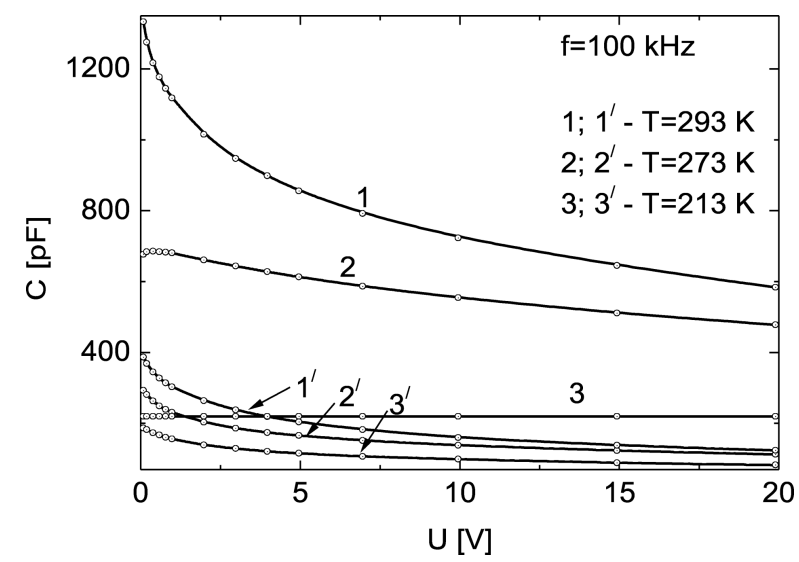

Fig. 2. Capacitance-voltage characteristics of diodes irradiated with protons, at different temperatures: No 15 (graphs 1,2,3) and No 9 (graphs 1', 2', 3').

increasing frequency. Yet another peculiarity is evident: at higher proton irradiation fluencies the capacitance dependence on frequency is stronger, i. e. the capacitance decreases faster with increasing frequency.

Based on these results we state that the higher irradiation fluencies create the larger density of radiation defects and therefore increase the reverse current strength in the junctions of structures. The low rate recharge of radiation defects and their complexes highlights these phenomena in low frequency range.

Reverse voltage affecting a proton irradiated diode transforms the thickness of depletion region in semiinsulating $i$-layer. The technique of irradiation with protons was such that the affected region was within semiinsulating layer. Therefore some radiation defects can recharge and cause an alteration of charge in this layer similar to the alteration caused by a minority charge carrier injection. As a result the total capacitance of $p-i-n$ diode in addition to its barrier capacitance is increased

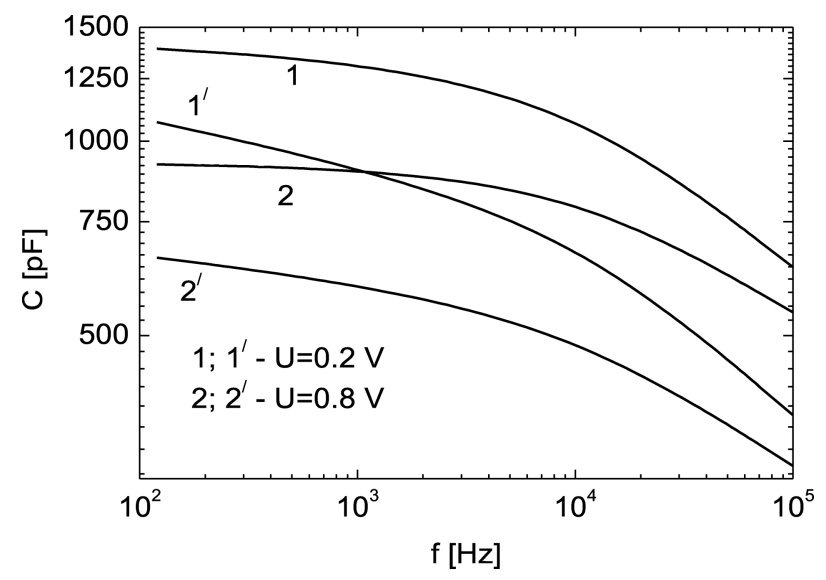

(a) by the value of component analogous to the diffusion capacitance [7]:

$$
C=C_{\mathrm{b}}+C_{\mathrm{d}}=C_{\mathrm{b}}+\frac{\mathrm{d}(\Delta Q)}{\mathrm{d} U} \approx C_{\mathrm{b}}+\frac{I_{a}(\tau) \tau_{0}}{2 \varphi_{T}},
$$

where $C_{\mathrm{b}}$ is the barrier capacitance of structure, $C_{\mathrm{d}}$ is a capacitance component due to electric charge variation $\Delta Q$ caused by recharge of radiation defects (the variation is proportional to the reverse current $\left.I_{a}(\tau)\right), \tau_{0}$ is a minority carrier lifetime in semiinsulating semiconductor, $\varphi_{T}$ is thermal potential.

The necessity of taking into account the capacitance component $C_{\mathrm{d}}$ is discussed also in $[4,8,9]$.

Other experimental results (Fig. 3) show that annealing of specimens reduces the junction capacitance and changes the character of dependence on frequency, i.e. the capacitance at higher frequencies decreases faster, which means that annealing changes the density of radiation defects and the physical properties of radiation defect complexes.

One can notice that a higher level irradiation of $p$ - $i$ - $n$ diodes induces a stronger capacitance dependence on temperature (Fig. 2). Capacitance practically does not depend on reverse voltage at $200 \mathrm{~K}$ temperature, whereas the $C-V$ characteristic of non-irradiated specimen even at $140 \mathrm{~K}$ temperature (Fig. 1(a)) slightly differs from the data at room temperature.

The diode capacitance dependences on reciprocal temperature measured at different testing signal frequency and the same bias have a sharp step in a particular temperature region (Fig. 4). In these measurements the reverse voltage was set to $10 \mathrm{~V}$ to ensure that almost all radiation defects are in depletion region. At low temperature all junction capacitances approach the same minimal value. The capacitance step moves to-

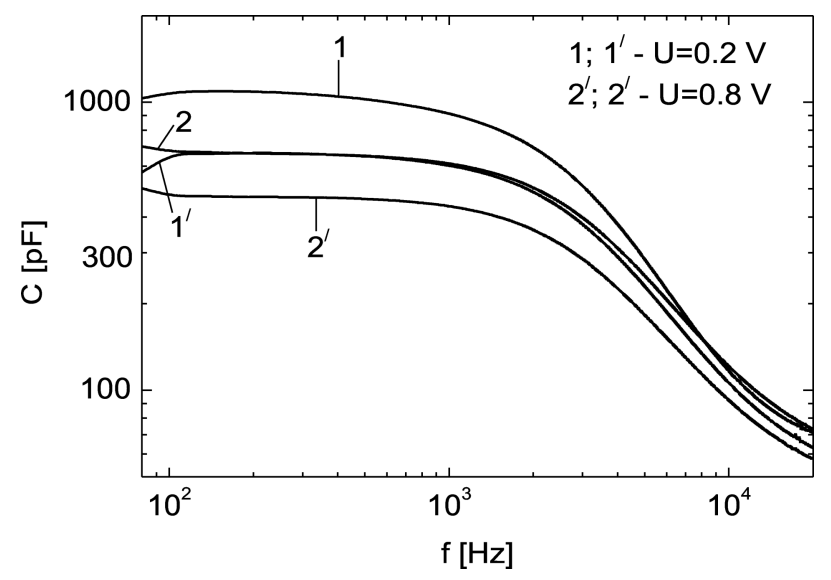

(b)

Fig. 3. Capacitance dependences on frequency at different reverse voltage of diodes No 27 (graphs 1,2) and No 9 (graphs 1', 2') (a) irradiated with protons and (b) after the second annealing. 


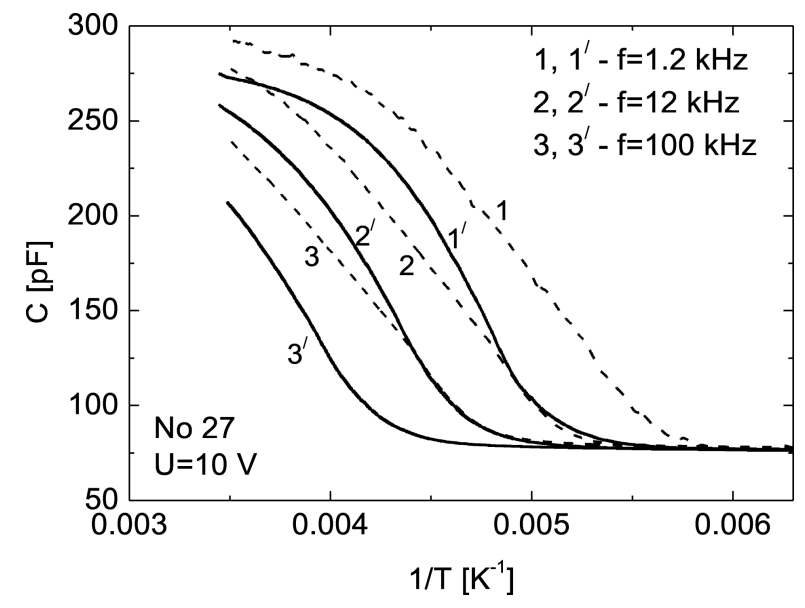

Fig. 4. Capacitance dependences of diode No 27 on reciprocal temperature at different frequencies after the first annealing (solid curve) and after the second annealing (dashed curve).

wards a higher temperature when the testing signal frequency increases. The step moves to the higher temperature after the second annealing as well. Capacitance dependences on temperature at different frequency for one specimen are presented in Fig. 4. Using these dependences one may calculate the energy of radiation defect as follows.

It was shown by Borchi et al. [10] that highenergy-particle irradiated silicon diode capacitance dependence on frequency is determined by the radiation defects' deep level recharge lifetime $\tau$. The lifetime is reciprocal to deep level electron emission coefficient:

$$
\tau \approx \frac{1}{e_{n}(T)} .
$$

The electron emission coefficient is [11]

$$
e_{n}(T)=\sigma \gamma T^{2} \exp \left(-\frac{E_{C}-E_{t}}{k T}\right),
$$

where $E_{t}$ is deep level energy, $\gamma=v_{\text {th }} N_{C} / T^{2}=$ $16 \pi k^{2} m_{e}^{*} / h^{3}, N_{C}$ is effective density of states in the valence band, $v_{\text {th }}$ is electron thermal velocity, $\sigma$ is capture cross-section, and $k$ is Boltzmann's constant.

Assuming that the temperature $T_{\mathrm{B}}$, at which the variation of capacitance $C(T)$ is the fastest, corresponds to the frequency $f$ inverse to the lifetime of recharging of a dominant defect level, we have [10] $f \approx 1 / \tau=$ $e_{n}\left(T_{\mathrm{B}}\right)$.

According to (3), it follows that

$$
\ln \left(\frac{f}{T_{\mathrm{B}}^{2}}\right)=-\frac{E_{C}-E_{t}}{k T_{\mathrm{B}}}+\ln (\sigma \gamma) .
$$

Using the values of some pairs $\left(f, T_{\mathrm{B}}\right)$ for graph of Eq. (4) it is possible to estimate the energy position of a dominant deep level. Assuming uncertainty of measurement we suggest the most probable value for the energy of dominant defect level as $\Delta E=E_{C}-E_{t}=$ $0.42 \pm 0.02 \mathrm{eV}$.

\section{Conclusions}

According to the measurements of capacitance dependences on reverse voltage, testing signal frequency, and temperature in silicon $p$ - $i$ - $n$ structures irradiated with high energy protons, we conclude:

- capacitances of these structures increase and significantly exceed the value of barrier capacitance with increasing either integral irradiation fluency or energy of irradiating protons (particularly this is seen at low reverse voltage and low frequency);

- recharging of radiation defects and their deep levels $\left(\Delta E=E_{C}-E_{t}=0.42 \pm 0.02 \mathrm{eV}\right)$ creates an additional component of capacitance analogous to diffusion capacitance of a $p$ - $n$ junction, which exhibits itself at a low frequency due to the low level recharging frequency.

\section{Acknowledgement}

This work was partially supported by the Lithuanian State Science and Studies Foundation.

\section{References}

[1] J. Vobecky, P. Hazdra, and V. Záhlava, Helium irradiated high-power $P-i-N$ diode with low ON-state voltage drop, Solid-State Electron. 47, 45-50 (2003).

[2] M. Msimanga and M. McPherson, Diffusion characteristics of gold in silicon and electrical properties of silicon diodes used for developing radiation-hard detectors, Mater. Sci. Eng. B 127, 47-54 (2006).

[3] Yu.K. Akimov, Silicon radiation detectors, Instrum. Exp. Tech. (Russia) 50(1), 1-28 (2007).

[4] N.A. Poklonski, S.A. Vyrko, and A.G. Zabrodskii, Calculation of capacitance of self-compensated semiconductors with intercenter hops of one and two electrons (by the example of silicon with radiation defects), Semicond. 42(12), 1388-1394 (2008).

[5] L.S. Berman and A.A. Lebedev, Capacitive Spectroscopy of Deep Centres in Semiconductors (Nauka, Leningrad, 1981) [in Russian].

[6] J. Višniakov, T. Čeponis, E. Gaubas, and A. Uleckas, Anneal-induced variations of the recombination characteristics in $2 \mathrm{MeV}$ proton irradiated $\mathrm{Si}$ structures, Lithuanian J. Phys. 48(4), 325-331 (2008). 
[7] P. Blood and J.W. Orton, The Electrical Characterization of Semiconductors: Majority Carriers and Electron States (Academic Press, London, 1992).

[8] D. Campbell, A. Chilingarov, and T. Sloan, Frequency and temperature dependence of the depletion voltage from CV measurements for irradiated $\mathrm{Si}$ detectors, Nucl. Instrum. Methods A 492, 402-410 (1997).

[9] M. McPherson, Capacitive effects in neutron-irradiated silicon diodes, Nucl. Instrum. Methods A 488, 100-109
(2002).

[10] E. Borchi, M. Bruzzi, S. Pirollo, and S. Sciortino, Temperature and frequency dependence of the capacitance of heavily irradiated silicon diodes, Solid-State Electron. 42(11), 2093-2096 (1998).

[11] D.K. Schroder, Semiconductor Material and Device Characterization, 3 ed. (Wiley-IEEE Press, New Jersey, 2006).

\title{
PROTONAIS ŠVITINTŲ Si DARINIŲ VOLTFARADINĖS CHARAKTERISTIKOS IR JŲ DAŽNINĖS BEI TEMPERATŪRINĖS PRIKLAUSOMYBĖS
}

\author{
S. Sakalauskas ${ }^{a}$, R. Pūras ${ }^{b}$ \\ ${ }^{\text {a } V i l n i a u s ~ u n i v e r s i t e t o ~ F i z i k o s ~ f a k u l t e t a s, ~ V i l n i u s, ~ L i e t u v a ~}$ \\ ${ }^{\mathrm{b}}$ Vilniaus universiteto Medžiagotyros ir taikomuju mokslu institutas, Vilnius, Lietuva
}

\section{Santrauka}

Pateiktos eksperimentinès didelès energijos protonais švitintų silicio $p-i-n$ diodų voltfaradinès charakteristikos, jų dažninès bei temperatūrinès priklausomybės ir iš to sekantys kai kurie apibendrinimai. Didesnis diodų apšvitos protonais srautas, esant vienodoms kitoms sąlygoms, indukuoja didesnes diodų, ijungtų atgaline kryptimi, talpas žemujju (20-120 Hz) dažnių srityje, kurios žymiai viršija nešvitintų diodų barjerinių talpu vertes. Iš voltfaradinių charakteristikų priklausomybės nuo dažnio ir temperatūros analizès apskaičiuota dominuojančio defekto gilaus lygmens energija. 